\title{
Investigating the Association between Ambiguity Tolerance and Vocabulary Knowledge in Iranian EFL Learners
}

\author{
Mehdi Jowkar \\ Nourabad Mamasani Branch, Islamic Azad University \\ Nourabad Mamasani, Iran \\ Hassan Khajehie \\ Department of English, Kazerun Branch \\ Islamic Azad University, Kazerun, Iran
}

\begin{abstract}
Learning a new language can be likened to the exploring of an unknown land, as there are varying ambiguous situations in the learning tasks. Ambiguity tolerance, as an important learning style, can inhibit or facilitate language learning. The present study seeks to unravel how tolerant/intolerant EFL learners are of such ambiguities as well as exploring whether tolerance of ambiguity of EFL learners affects their vocabulary knowledge. The study also aimed to investigate whether there is any gender-related difference in tolerance of ambiguity of EFL learners and whether ambiguity tolerance is somehow associated with self-perceived success of Iranian EFL learners in vocabulary. This study was carried out with 60 freshmen enrolled in the English Language Teaching (ELT) Department of Kazerun Islamic Azad University in Iran. The data collection instruments consisted of the Second Language Tolerance of Ambiguity Scale and the Vocabulary Levels Test. The obtained data were subsequently analyzed descriptively using the SPSS, version 21 software. The results revealed that EFL learners have a moderate level of ambiguity tolerance in foreign language learning and that gender does not have any significant impact on tolerance of ambiguity. It was also found that there is no significant relationship between tolerance of ambiguity and vocabulary knowledge whereas a significant relationship between tolerance of ambiguity and selfperceived achievement in foreign language vocabulary learning was detected. Implications based on the findings are also suggested.
\end{abstract}

Keywords: Ambiguity tolerance; gender difference; vocabulary knowledge; EFL learners; foreign language learning

\section{INTRODUCTION}

Current trends in EFL settings indicate that the most important change has been a shift from an emphasis on the language teaching methodology to language learners and learner variables that affect language learning. BAŞÖZ (2015) believes that individual differences and learning styles have widely gained importance as they are considered to play a vital role in helping learners to have better achievement in language learning. One of the most important learning styles is ambiguity tolerance (AT) which is defined by Brown as "the degree to which you are cognitively willing to tolerate ideas and propositions that run counter to your own belief system or structure of knowledge" (2000, p. 119). According to Ely (1989) language learning is full of uncertainty and there is a considerable amount of ambiguity in learning a foreign language. Due to the inadequacy of linguistic cues in an L2 context learners are likely to have some difficulties in constructing meaningful interpretation (Chapelle \& Roberts, 1986). Ambiguity is what makes learning exciting for some foreign language learners while for others it is what makes learning extremely frustrating. Hence, ambiguity is one of the key 
characteristics of a foreign language learning situation and it is likely to hinder or facilitate language learning. White (1999) stresses that it may cause a high level of stress in learners and negatively affects language learning if it is not tolerated in a reasonable manner.

Marzban et al (2012) believe that an awareness of the impact of AT as a psychological construct on EFL learning is of great importance and would result in teachers' modifications in planning and execution of lessons in order to better help the students' overcome psychological barriers. It is therefore deemed necessary to look for possible differences in ambiguity tolerance among learners in order to minimize the gap in teacher- learner interaction and the amount of attention which is paid to important individual traits in classroom context.

Kazamia (1999) states that structure, the lexical items, the phonological and phonetic elements of any two languages do not relate one-to-one. Whether learning takes place in the classroom or in naturalistic settings, whether language learning is geared towards communicative use or not, the learner has to deal with uncertainties stemming partly from this lack of total correspondence between any two languages. A feature that helps learners to overcome uncertainties inherent in language learning is tolerance of ambiguity.

Learning a new language is akin to exploring an unknown land as ambiguous situations are prevalent in language learning. Ambiguity tolerance, which can hinder or facilitate language learning, is considered as an important learning style. Also referred to as language ego, ego boundaries, or cognitive flexibility (Guiora, 1981; Ehrman, 1993), tolerance of ambiguity is directly related to the study described here because various studies have shown that learners who can tolerate moderate levels of ambiguity are more likely to persist in language learning (Chapelle, 1983; Naiman, Frohlich, Stern, \& Tedesco, 1978) and to achieve more than those who cannot tolerate ambiguity (Chapelle \& Roberts, 1986; Reiss, 1985; Ehrman, 1993).

Ellis (1994) described tolerance of ambiguity as a dimension of second language learning which "entails an ability to deal with ambiguous new stimuli without frustration and without appeals to authority. It allows for indeterminate rather than rigid categorization" (p. 518)

\section{Ambiguity and Tolerance}

\section{LITERATURE REVIEW}

To define tolerance of ambiguity we are faced with a double task; to designate what tolerance is and to interpret the meaning of ambiguity. McLain (1993, p. 184) postulates that tolerance suggests 'begrudging acceptance' and adds that tolerance 'extends along a continuum from rejection to attraction'. McLain (1993) suggests that ambiguity signifies perceived insufficiency of information regarding a particular stimulus or context. Budner (1962) defines ambiguous stimuli or 'ambiguous situations' according to his terminology, as those that are not adequately structured or categorized by the perceiver because they lack sufficient cues.

In research literature, ambiguity is described in various terms. It refers to uncertainty about the future (Johnson 2001, p. 141), perceived insufficiency of information regarding a particular stimulus or context (McLain 1993, p. 183), stimulus with lack of information (McLain 1993, p. 184), and "too little, too much, or seemingly contradictory information" (Norton 1975, p. 607). Ambiguous situation is, therefore, characterized by a lack of adequate cues, which results in insufficient reorganization or categorization by an individual (Budner 1962, p. 30). It is easy to imagine what this can mean in a FL classroom or in a context of FL reading: due to the unfamiliar linguistic elements, for instance, a learner does not understand the teacher's directions, feels that a text completely lacks familiarity and logic, cannot make decisions with a 
predictable result, and cannot have any solid expectations about a new text since the information provided by any cues is inaccessible.

Ehrman (1993 \& 1999) gives a perspective on tolerance of ambiguity. She has devised a tolerance of ambiguity construct which is separated into three levels: the first level called intake; the second level named tolerance of ambiguity proper and the third level termed accommodation. At the intake level the learner admits new information into his/her mind. In the tolerance of ambiguity proper, which is the second level, it is assumed that intake has happened and at this stage the individual has to deal with contradictory elements, incomplete information or incomplete systems. The third level is described as accommodation borrowing this term from Piaget (1967) - and it is at this level where discriminations of the new data are made, priorities are set and ultimately integration of new information with existing structures occurs in order to alter the latter and create new cognitive schemata that did not exist before. It may be concluded then that tolerance of ambiguity is a feature closely related to one's personality or one's cognitive style (Ely 1989).

In fact Ely (1989) suggests that ambiguity in language learning is materialized as uncertainty. He explains this by saying that language learning is 'fraught with uncertainty' and examples of the causes of this may be the fact that rarely do learners know the exact meaning of a new lexical item or feel that they have pronounced a sound with total accuracy or have fully comprehended the temporal reference of a grammatical tense. The pervasive character of uncertainty, or, to put it differently, ambiguity, affects language learning positively or negatively. Ely (1995, p. 88) specifies three cases where tolerance of ambiguity has a negative impact on language learning:

1) learning individual linguistic elements (phonological, morphological, syntactic, semantic, etc.).

2) practicing language learning skills.

3) adopting those skills as permanent strategies.

It is not difficult to visualize instances where intolerance of ambiguity impedes the learning of individual linguistic elements. When a learner fails to grasp new sounds in order to pronounce new words he/she may experience such discomfort that he/she may give up attempts to master the new L2 sounds and resort to L1-like sounds in order to utter the specific word.

It is suggested that moderate levels of tolerance of ambiguity are recommended for optimum results in language learning. Since high tolerance may cause cognitive passivity and low tolerance may impede language learning, mid point tolerance seems to be satisfactory (Ely, 1995 \& Ehrman, 1996).

\section{Ambiguity Tolerance (AT) and Language Learning}

Grace (1998) examines the effects of lexical ambiguity in CALL on beginning second language learners. This study attempts to determine whether learners' personality types-as measured by the Myers-Briggs Type Indicator-have an effect on the retention of second language vocabulary independently of the translation issue and in an ambiguous CALL context. Analyses of vocabulary retention tests show that students of all personality types learned and retained a significant amount of vocabulary when verification of meaning was provided through the first language regardless of their tolerance for ambiguity.

Kazamia (1999) tries to identify and assess the degree of tolerance of ambiguity Greek civil servants demonstrate when learning English as a foreign language. The concept of tolerance of 
ambiguity is introduced and its relevance to language learning is discussed. Qualitative analysis of research data indicates that Greek adult learners do not show the same tolerance in all skills, and are particularly intolerant of ambiguities stemming from communicating their ideas in English.

Erten \& Topkaya (2009) statistical analysis indicates students on average have lower tolerance for ambiguity in the process of learning, with female students reporting less tolerance than male students. Students" AT, their self-perceived success, and strategy training they received correlated significantly.

Kamran (2011) investigates the pattern of ambiguity tolerance among Iranian English language learners. Further, she examines whether any statistically significant difference existed between Iranian male and female learners' in their ambiguity tolerance. To this end, two instruments of Second Language Ambiguity Tolerance Scale (SLATS) developed by Ely (1995), and a questionnaire on participants' demographic information were used to collect the data. Results indicates the participants' average ambiguity tolerance score were highest in items related to reading skill and the lowest in items pertained to writing skill. On the part of gender effect, no statistically significant difference was revealed between Iranian male and female English language learners in their ambiguity tolerance.

Marzban et al (2012) aims at exploring how tolerant of ambiguity Iranian EFL learners at university level are and if gender plays a role in this regard. To this end, upon filling in the revised SLTAS scale of ambiguity tolerance 194 male and female Iranian teacher trainees were assigned to three ambiguity tolerance groups; namely, high, moderate and low. Cluster analysis of the SLTAS scores indicated that Iranian EFL learners were mostly moderate as far as tolerance of ambiguity was concerned. Examining the gender differences through an independent sample $t$-test manifested that female participants were less tolerant of ambiguity than their male peers. Also, the differences between the expected and observed number of participants categorized in the three AT groups were non-significant undermining the role of gender as a moderator variable in assigning participants to AT groups and further approving of SLTAS validity.

BAŞÖZ (2015) studies how tolerant/intolerant EFL learners are of foreign language ambiguities in addition to exploring whether tolerance of ambiguity of EFL learners affects their vocabulary knowledge. The study also aims to probe whether there is any gender-related difference in tolerance of ambiguity of EFL learners and investigates whether ambiguity tolerance is related to self-perceived success of Turkish EFL learners in foreign language vocabulary. The findings of the study revealed that EFL learners have a moderate level of ambiguity tolerance in foreign language learning and that gender does not have any significant impact on tolerance of ambiguity. It was also found that there is no significant relationship between tolerance of ambiguity and vocabulary knowledge whereas a significant relationship between tolerance of ambiguity and self-perceived achievement in foreign language vocabulary learning was identified.

Ely (1989) defines tolerance of ambiguity as one's acceptance of confusing situations and a lack of clear lines of demarcation in the context of reactions to specific language classroom events. Naiman et al. (1978) and Ehrman (1999) more broadly referred to the concept as a facet of personality characteristics. Ehrman (1999) specifically linked it to risk taking because those who can tolerate ambiguity are more likely to take risks in language learning, an essential factor for making progress in the language (Ely, 1989). 
Ambiguity tolerance, depicted in language learning environment, is the ability of dealing with new ambiguous situations without being frustrated or without resorting sources of knowledge (Ellis, 1994). Ambiguity in language learning is appeared as uncertainty, which is experienced by language learners whenever they feel they have not pronounced a sound accurately, or understood exploitation of a grammatical point or grasped the exact meaning of a word (Ely, 1989). Therefore, when ambiguity is not tolerated reasonably, it can involve learners in a stressful situation in which language learning, risk taking, and application of the appropriate strategies may be negatively influenced.

Gender is considered as one of the chief factors influencing the acquisition of a language. Brown (2001) believes that gender is one of significant pragmatic variables which influence the acquisition of communicative competence in every language. However, few studies investigated gender differences in language learning style of ambiguity tolerance. Among the existing studies, Maubach \& Morgan (2001) who investigated the impact of gender on language learning style of 72 A level students of French and German, revealed that male students had higher level of ambiguity tolerance comparing to their female counterparts. In contrast, Kissau (2006) in his study on French language learners in Ontario reported no gender difference in tolerance of ambiguity. Finally, Erten \& Topkaya (2009) in their study on Turkish university students reported a significant difference between male and female students in their tolerance of ambiguity with females exceeding males.

Considering the vital role of ambiguity tolerance in language learning context and the few number of studies (with paradoxical results) which investigated the gender role in ambiguity tolerance of English on a personality variable called ambiguity tolerance, the present study seeks to investigate the following research questions. Strictly speaking, the study, on one hand, aims to show how tolerant/intolerant EFL learners are of foreign language ambiguities. On the other hand, it explores whether gender difference might exert any impact on ambiguity tolerance. Finally, the study investigates whether tolerance of ambiguity is related to selfperceived success of Iranian EFL learners in foreign language vocabulary.

\section{RESEARCH QUESTIONS}

1. How tolerant/intolerant of ambiguity are Iranian EFL learners?

2. Is there any gender-related difference in tolerance of ambiguity of Iranian EFL learners?

3. Does level of tolerance of ambiguity of Iranian EFL learners affect their receptive vocabulary knowledge?

4. Is tolerance of ambiguity related to self-perceived achievement of Iranian EFL learners in foreign language vocabulary?

\section{Participants}

\section{METHOD}

This study was conducted with a total of 60 sophomore enrolled in the English language teaching (ELT) at Kazerun Islamic Azad University in Iran in the first semester of the 20152016 academic year. The participants mean age was 21.35 (minimum =18; maximum = 42), showing a close age range. Of the participants, 35 were female and 25 were male. More than half of the students perceived themselves as having average English vocabulary knowledge while 15 students reported that they considered themselves good at English vocabulary. Some students believed that they were poor at English vocabulary. 


\section{Instruments}

The data collection instruments consisted of the Second Language Tolerance of Ambiguity Scale (SLTAS) (Ely, 1995) with some embedded demographic questions and the Vocabulary Levels Test (Schmitt et al., 2001). The version of SLTAS used in this study had 12 items with a five-point Likert scale. The items aimed to measure students' agreement level with statements depicting intolerance of ambiguity in given situations. It was noted before that the SLTAS have high internal consistency with a Cronbach's alpha reliability coefficient of .84 (Kazamina, 1999).

In order to measure the receptive vocabulary knowledge of the participants, the vocabulary Levels Test Version 2 was used. It consisted of 5 sections: the 2,000; the 3,000-; the 5,000 and the 10,000 word level, and the academic vocabulary level. The participants had to match a target word with the equivalent definition in each section. A total of 60 target words were used per section. Each section included ten groups of six words and three definitions. Each correct answer was given one point and the maximum score of the test was 30 points. The total number of test items was 150 . The studies that gave information about the validity and reliability of the Vocabulary Levels Test (Read, 2000; Schmitt et al., 2001) suggested that the test measured what it intended to measure and was consistent in its measurements. The reliability indices (Cronbach's alpha) for all of the levels sections were high as illustrated by Table 1 (Read, 2000; Schmitt et al., 2001).

\section{Data collection procedures}

This study was conducted on undergraduate EFL students at Kazerun Islamic Azad University in Iran in the first semester of the 2015-2016 academic year. The Second Language Tolerance of Ambiguity Scale was administered to the sophomore enrolled in the English department. Immediately after the scale, all the participants voluntarily completed the Vocabulary Levels Test. There was a time limit of 100 minutes for the whole test.

\section{Data analysis}

The data were checked for normality assumptions for parametric tests, initially. Both Kolmogorov- Smirnov $(\mathrm{p}<.180)$ and normal Q-Q plot indicated a normal distribution within the data, fitting neatly into a normal distribution. The data were analyzed descriptively using the SPSS 21 Software. Through a descriptive analysis, the mean scores and standard deviations were found for the scale items. Then, in order to see the correlations between the dependent and independent variables the values of independent samples tests and one-way analysis of variance were calculated.

\section{RESULTS}

\section{How tolerant/intolerant of ambiguity are Iranian EFL learners?}

To determine the level of ambiguity of tolerance of the participants, descriptive statistics were utilized. The participants were told that the items in the SLTAS investigate their reactions to statements depicting intolerance of ambiguity in some language learning situations. That is, agreement with an item was a sign of intolerance. Thus, it was reasonable to consider a mean of 3.00 as a dividing line between tolerance and intolerance. Any value above the dividing line would be a sign of lower levels of tolerance whereas those below would point to more tolerance according to their distance to the mean score of 3.00 . 


\begin{tabular}{|lcc|}
\hline Level & Number of items & Cronbach's Alpha \\
\hline 2000 & 30 & .922 \\
\hline 3000 & 30 & .927 \\
\hline 5000 & 30 & .927 \\
\hline 10000 & 30 & .924 \\
\hline Academic & 30 & .960 \\
\hline
\end{tabular}

Table 1. Reliability of the levels sections (Cronbach's alpha)

The participants' mean scores from the SLTAS are presented in Table 2.

\begin{tabular}{|c|}
\hline Mean \\
\hline When I'm reading something in English, I feel impatient when I don't totally \\
\hline understand the meaning. \\
\hline It bothers me that I don't understand everything the teacher says in English. \\
\hline When I write English compositions, I don't like it when I can't express my ideas exactly. \\
\hline $\begin{array}{l}\text { It is frustrating that sometimes I don't understand completely some English grammar } \\
1.09\end{array}$ \\
\hline $\begin{array}{ll}\text { I don't like the feeling that my English pronunciation is not quite correct. } & 60\end{array}$ \\
\hline $\begin{array}{l}\text { I don't enjoy reading something in English that takes a while to figure out completely. } \\
1.03\end{array}$ \\
\hline It bothers me that even though I study English grammar, some of it is hard to use in \\
\hline $\begin{array}{lll}\text { speaking and writing. } & 60 & 2.86 \\
\end{array}$ \\
\hline When I'm writing in English, I don't like the fact that I can't say exactly what I want. \\
\hline $\begin{array}{llll}\text { It bothers me when the teacher uses an English word I don't know. } & 60 & 2.98 & 1.09\end{array}$ \\
\hline \multirow{2}{*}{$\begin{array}{lll}\text { When I'm speaking in English, I feel uncomfortable if I can't communicate my ideas clearly. } 60 & 2.35 & 1.17 \\
\text { I don't like the fact that sometimes I can't find English words that mean the same words }\end{array}$} \\
\hline \\
\hline $\begin{array}{llll}\text { in my own language. } & 60 & 2.30 & 1.09 \\
\end{array}$ \\
\hline $\begin{array}{lll}\text { One thing I don't like about reading in English is having to guess what the meaning is. } & 60 & 3.03 \\
\end{array}$ \\
\hline TOTAL AMBIGUITY TOLERANCE SCORE \\
\hline
\end{tabular}

Table 2. Ambiguity Tolerance scores from the SLTAS

The participants reported a level of tolerance of ambiguity that was a little below the mid-point $(M=2.79, S D=1.08)$. This value indicated that the participants, generally, did not show high tolerance/intolerance of ambiguity, neither welcoming without inquiring nor being hindered by insufficient linguistic information. Nevertheless, an item-by-item analysis of the SLTAS indicated a mean range between 3.21 and 2.26, which showed the possibility that learners differ in their levels of ambiguity tolerance (Ehrman, 1999 \& Ely, 1995). A K-means cluster analysis was conducted to investigate whether participants can be divided into such ambiguity groups as low, moderate, and high. The result of the analysis demonstrated that the participants can be categorized into three different clusters in terms of their AT scores (See Table 3).

\begin{tabular}{|lcccccc|}
\hline Ambiguity Cluster & $\mathrm{N}$ & \% of Total N & Mean & SD & Minimum & Maximum \\
\hline High (H) & 12 & $20.0 \%$ & 17.75 & 2.92 & 11.00 & 20.00 \\
\hline Moderate (M) & 30 & $50.0 \%$ & 25.03 & 2.51 & 22.00 & 29.00 \\
\hline Low (L) & 18 & $30.0 \%$ & 33.88 & 3.23 & 30.00 & 40.00 \\
\hline Total & 60 & $100.0 \%$ & 26.23 & 6.40 & 11.00 & 40.00 \\
\hline
\end{tabular}

Table 3. Clusters of students according to their tolerance of ambiguity

An analysis of variance (ANOVA) between the three groups validated that participants clustered in three groups were different from one another $(p<.000)$ with regard to their ambiguity tolerance. The differences are presented in Table 4. 


\begin{tabular}{|lccccc|}
\hline \multicolumn{1}{c}{ Sum of Squares } & df & Mean Square & F & Sig. \\
\hline Between Groups & 1961.739 & 2 & 980.869 & 122.880 & .000 \\
\hline Within Groups & 454.994 & 57 & 7.982 & & \\
\hline Total & 2416.733 & 59 & & & \\
\hline
\end{tabular}

Table 4. Differences between three AT clusters

To sum up, descriptive statistics, together with cluster analysis and analysis of variance, indicated three different groups of participants in terms of their AT. The majority of the participants $(n=30 ; 50.0 \%)$ had moderate levels of tolerance $(M=25.03, S D=2.51)$. Some of the participants $(n=18 ; 30.0 \%)$ had low levels of tolerance $(M=33.88, S D=3.23)$, whereas a nearly similar proportion $(\mathrm{n}=12 ; 20.0 \%)$ reported that they could tolerate ambiguity to a great extent $(M=17.75, S D=2.92)$. Therefore, it can be deduced that there are variations among EFL learners regarding their level of ambiguity tolerance.

Is there any gender-related difference in tolerance of ambiguity of Iranian EFL learners? This study also aimed to discover whether gender plays any role in tolerance of ambiguity of EFL learners. First, an analysis of frequency was conducted to see the distribution of male and female participants to each of the already determined tolerance groups. The results are illustrated in Table 5.

\begin{tabular}{|lllll|}
\hline Tolerance group & Male & $\%$ & Female & $\%$ \\
\hline Low & 4 & 22.22 & 14 & 77.77 \\
\hline Moderate & 8 & 26.66 & 22 & 73.33 \\
\hline High & 7 & 58.33 & 5 & 41.66 \\
\hline Total & 19 & 100 & 41 & 100 \\
\hline
\end{tabular}

Table 5. Distribution of males and females to different tolerance groups

A great number of female EFL learners fell into low (77.77 \%) and moderate (73.33\%) tolerance groups whereas these figures were low with male EFL learners $(22.22 \%$ and 26.66 $\%$ respectively). 7 of 19 male EFL learners (58.33\%) had high tolerance of ambiguity whereas the number of female learners in this tolerance group was five (41.66\%). It is clear from the table that female EFL learners had lower levels of tolerance of ambiguity in foreign language learning. However, an independent samples t-test was performed so as to find out whether there is any significant gender-related difference in tolerance of ambiguity of the participants. The results are shown in the table below.

\begin{tabular}{|ccccccccc|}
\hline & Gender & $\mathrm{N}$ & Mean & SD & MD & t & df & Sig. \\
\hline Ambiguity Score & Female & 41 & 27.31 & 5.52 & & & & \\
\hline & & & & & -3.4222 & -1.973 & 58 & .053 \\
\hline Male & 19 & 23.89 & 7.60 & & & & \\
\hline
\end{tabular}

Table 6. Gender differences in tolerance of ambiguity

According to the table, there was no statistically significant difference between male $(\mathrm{M}=$ 23.89, $\mathrm{SD}=7.60)$ and female participants' $(M=27.31, S D=5.52), t(58)=-1,973, p=.053, d=$ 0.5 ambiguity tolerance levels with a medium effect size. That is to say, gender did not have any significant impact on the EFL learners' ambiguity tolerance levels.

\section{Does level of tolerance of ambiguity of Iranian EFL learners affect their receptive vocabulary knowledge?}

The present study also aimed at exploring whether level of ambiguity tolerance has any significant impact on EFL learners' receptive vocabulary knowledge. In this regard, the mean 
scores of the three tolerance groups were compared through one-way analysis of variance (One-way ANOVA). Descriptive statistics, mean scores and standard deviations, for the three groups are presented in Table 7.

\begin{tabular}{|lccc|}
\hline Tolerance group & Mean & $\mathrm{N}$ & SD \\
\hline High & 108.91 & 12 & 22.12 \\
\hline Moderate & 96.90 & 30 & 19.90 \\
\hline Low & 89.83 & 18 & 23.64 \\
\hline Total & 97.18 & 60 & 22.17 \\
\hline
\end{tabular}

Table 7. Vocabulary knowledge according to tolerance of ambiguity

According to the table, it seemed that the more tolerant EFL learners were of ambiguity, the more receptive vocabulary knowledge they had in a foreign language. However, the results of the one-way analysis of variance revealed that there was no statistically significant difference at the $p<.05$ level among the three tolerance groups in terms of vocabulary knowledge: $F$ $(2,57)=2.83, p=.067$. The effect size, calculated using eta squared, was .09.

\begin{tabular}{|llllll|}
\hline \multicolumn{2}{|c}{ Sum of Squares } & df & Mean Square & F & Sig. \\
\hline Between Groups & 2626.867 & 2 & 1313.433 & 2,838 & .067 \\
\hline Within Groups & 26384.117 & 57 & 462.879 & & \\
\hline Total & 29010.983 & 59 & & & \\
\hline
\end{tabular}

Table 8. Analysis of Variance: Vocabulary knowledge and AT

\section{Is tolerance of ambiguity related to self-perceived achievement of Iranian EFL learners in foreign language vocabulary?}

Mean scores and standard deviations were calculated to see the self-perceived achievement of the participants with regard to the previously identified tolerance groups. The descriptive statistics can be seen in the table below.

\begin{tabular}{|lccc|}
\hline Tolerance group & Mean & $\mathrm{N}$ & SD \\
\hline Moderate & 2.26 & 30 & .69 \\
\hline High & 2.16 & 12 & .50 \\
\hline Low & 1.61 & 18 & .71 \\
\hline Total & 2.05 & 60 & .69 \\
\hline
\end{tabular}

Table 9. Perceived achievement in vocabulary according to tolerance of ambiguity

The table shows the difference among three different tolerance groups in self-perceived vocabulary achievement, suggesting that EFL learners who have moderate level of ambiguity tolerance perceived themselves to be more successful in foreign language vocabulary. The learners with low tolerance of ambiguity, on the other hand, reported the lowest level of selfperceived achievement. In order to understand the relationship between tolerance of ambiguity and self-perceived achievement in foreign language vocabulary, a one-way betweengroups analysis of variance was conducted. According to Table 10, there was a statistically significant relationship at the $p<.05$ level between tolerance of ambiguity and perceived achievement in foreign language vocabulary: $F(2,57)=7.05, p=.002$. The eta squared statistic (.17) indicated a large effect size.

\begin{tabular}{|lcrccc|}
\hline & Sum of Squares & df & Mean Square & F & Sig. \\
\hline Between Groups & 479.453 & 2 & 239.727 & 7,053 & .002 \\
\hline Within Groups & 1937.280 & 57 & 33.987 & & \\
\hline Total & 2416.733 & 59 & & & \\
\hline
\end{tabular}

Table 10. Analysis of Variance: perceived achievement in vocabulary and AT 


\section{DISCUSSION}

This study aimed to investigate how tolerant are Iranian EFL learners of foreign language ambiguities. The findings of the study revealed that Iranian EFL learners had a moderate level of ambiguity tolerance neither welcoming without inquiring nor being hindered by insufficient linguistic information. This is in keeping with the studies that have explored EFL learners' level of ambiguity tolerance (Erten \& Topkaya, 2009; Kazamina, 1999). In the study, the EFL learners were categorized into three different clusters with regard to their ambiguity scores on the grounds that individuals may show various levels of tolerance to ambiguity (Ehrman, 1999 \& Ely, 1995) and it seems from the findings of the current study that learners tolerate ambiguity differently (Erten \& Topkaya, 2009).

The study also explored the impact of gender on tolerance of ambiguity of EFL learners. According to the findings, gender did not have any significant impact on the EFL learners' ambiguity tolerance levels. Therefore, the findings of the study contradict the related literature (Maubach \& Morgan, 2001; Erten \& Topkaya, 2009; Marzban et al., 2012) to a certain extent in spite of showing parallel results with some previous studies (Kamran, 2011; Kissau, 2006) that identified no gender-related difference in EFL learners' ambiguity tolerance levels.

Understanding the relationship between tolerance of ambiguity of EFL learners and their vocabulary knowledge was another aim of the present study. The results indicated that there was no statistically significant difference among three AT groups in terms of their receptive vocabulary knowledge although it seemed that the more tolerant EFL learners were of ambiguity, the more receptive vocabulary knowledge they had in a foreign language.

Another interest of this study was to explore whether tolerance of ambiguity is related to self perceived achievement of Iranian EFL learners in foreign language vocabulary. It was found that there was a significant relationship between tolerance of ambiguity and perceived achievement in foreign language vocabulary. EFL learners who have moderate level of ambiguity tolerance perceived themselves to be more successful in foreign language vocabulary. The learners with low tolerance of ambiguity, on the other hand, reported the lowest level of self-perceived achievement. This is in line with the previous research that revealed a positive influence of AT on language learning achievement (Chapelle \& Roberts, 1986; Erten \& Topkaya, 2009; Naiman et al., 1978). Evidently, language learners who can handle the ambiguities of learning a new language moderately feel themselves more successful in foreign language vocabulary learning. In this sense, the result supported the favored moderate level of ambiguity tolerance (Ehrman, 1999; Ely, 1995).

\section{CONCLUSIONS}

This study attempted to probe the ambiguity tolerance levels of EFL learners and to determine likely relationships between ambiguity tolerance and other variables such as gender, vocabulary knowledge and perceived achievement in foreign language vocabulary. Based upon the findings and discussion presented, there is a strong case for concluding that learners in an EFL context have a moderate level of ambiguity tolerance. The findings also suggested that gender did not have any significant impact on EFL learners' tolerance of ambiguity. Another facet of ambiguity that has been probed in this study was its relationship with foreign language vocabulary knowledge.

The findings revealed that there was no statistically significant difference among three AT groups in terms of their receptive vocabulary knowledge although it seemed that the more tolerant EFL learners were of ambiguity, the more receptive vocabulary knowledge they had in 
a foreign language. The last concern of the present study was to investigate the interaction between tolerance of ambiguity of EFL learners and their self-perceived achievement in foreign language vocabulary. A significant relationship between these variables was detected, which enables us to conclude that EFL learners who have moderate level of ambiguity tolerance feel themselves more successful in foreign language vocabulary learning.

In the light of the results, some pedagogical implications can be suggested. The realization of the strong influence of ambiguity tolerance on foreign language learning is of great value and should lead to teachers' alterations in planning and implementation of courses so as to better help the language learners overcome psychological barriers. If learners are well informed about classroom procedures, they will feel more relaxed, self-assured and motivated in the language classroom (Burden, 1997), which may in return help lower tolerance of ambiguity. The present study demonstrates that tolerance of ambiguity is closely connected with perceived success in foreign language vocabulary. Therefore, the use of ambiguity reducing strategies by teachers is of essential importance. As leading members in learning contexts, teachers are supposed to have an important role in assisting learners with their struggle for success in language learning especially when learners encounter with ambiguities. They should raise learners' consciousness of methods, procedures, and teaching content as well.

As for the limitations of the study, the participants were restricted to 60 Iranian EFL learners from one educational context. Thus, it would be better to carry out a study with larger samples from diverse educational contexts in further research. Moreover, the scope of the study was confined to the descriptive data obtained from the Second Language Tolerance of Ambiguity Scale (SLTAS) and the Vocabulary Levels Test (VLT) designed to measure only receptive vocabulary knowledge. Further research may be focused on the investigation of the relationship between ambiguity tolerance and different variables in the Persian context.

\section{References}

BAŞÖZ, T. (2015). Exploring the relationship between tolerance of ambiguity of EFL learners and their vocabulary knowledge. Journal of Language and Linguistic Studies, 11(2), 53-66.

Brown, H. D. (2000). Principles of language learning and teaching (4th Ed.). New York: Pearson Education Company.

Brown, H. D. (2001). Teaching by principles. New York: Pearson Education Company.

Budner, S. (1962). Intolerance of ambiguity as a personality variable. Journal of Personality 30, 29-50.

Chapelle, C. A. (1983). The relationship between ambiguity tolerance and success in acquiring English as a second language in adult learners. Unpublished doctoral dissertation. University of Illinois, Illinois.

Chapelle, C. A., \& Robert, C. (1986). Ambiguity tolerance and field independence as predictors of proficiency in English as a Second Language. Language Learning, 36, 27-45.

Ehrman, M.E. (1993). Ego boundaries revisited: toward a model of personality and learning. In Alatis (ed.) pp. 330-362.

Ehrman, M.E. (1999). Ego boundaries and tolerance of ambiguity in second language learning. In Arnold (ed.) pp. 68-86.

Ellis, R. (1994). The study of second language acquisition. Oxford: Oxford University Press.

Ely, C. M. (1989), "Tolerance of ambiguity and use of second language learning strategies", Foreign Language Annals 22, 437-445. http://dx.doi.org/10.1111/j.1944-9720.1989.tb02766.x

Ely, C. M. (1995). "Tolerance of ambiguity and the teaching of ESL", in Reid, J. (Ed.), Learning styles in the ESL/EFL classroom, Boston: Heinle \& Heinle, pp. 87-95. 
Erten, I., \& Topkaya, E. (2009), "Understanding tolerance of ambiguity of EFL learners in reading classes at tertiary level", Novitas-Royal 3(1), 29-44. [Online] Available:

http://www.novitasroyal.org/vol_3_1/erten_topkaya.pdf (Feb 4, 2017)

Guiora, A. Z. (1981). Language, personality, and culture, or the Whorfian hypothesis revisited. In M. Hines, W. Rutherford (Eds.), On TESOL '81 (pp. 169-177). Detroit, MI: Teachers of English to Speakers of other Languages.

Grace, C. (1998). Personality type, tolerance of ambiguity, and vocabulary retention in CALL. CALICO Journal, 15 (1-3), 19-46.

Johnson, K. (2001). An introduction to foreign language learning and teaching. Harlow: Pearson Education Limited.

Kamran, S. K. (2011). Effects of Gender on Ambiguity Tolerance of Iranian English Language Learners. Journal of Education and Practice, 2, 25-33.

Kazamia, V. (1999). "How tolerant are Greek EFL learners of foreign language ambiguities?", Leeds Working Papers in Linguistics 7, 69-78. [Online] Available: http://www.leeds.ac.uk/linguistics/WPL/WP1999/kazamia (Feb 16, 2017)

Kissau, S. (2006), "Gender differences in second language motivation: An investigation of micro- and macro-level influences", Canadian Journal of Applied Linguistics 9 (2), 73-96.

Marzban, A., Barati, H., \& Moinzadeh, A. (2012). An Investigation into Ambiguity Tolerance in Iranian Senior EFL Undergraduates. English Language Teaching 5 (1), 76-85.

Maubach, A. M., \& Morgan, C. (2001), "The relationship between gender and learning styles amongst A level modern languages students", The Language Learning Journal 23 (1), 41-47.

McLain, D.L. (1993). The MSTAT-1: A new measure of an individual's tolerance for ambiguity. Educational and Psychological Measurement 53, 183-189.

Naiman, N., Frohlich, M., Stern, H., \& Todesco, A. (1978). The good second language learner (Research in Education Series No.7). Toronto: Ontario Institute for Studies in Education.

Norton, R.W. (1975). Measurement of ambiguity tolerance. Journal of Personality Assessment 39(6), 607-619

Piaget, J. (1967). Six Psychological Studies. New York: Random House.

Reiss, M. A. (1985). The good language learner: Another look. Canadian Modern Language Review, 41, 511-523.

White, C. (1999), "Expectations and emergent beliefs of self-instructed language Learners", System 27, 443-4157. 